\title{
METODE PRAKTIK PADA PEMBELAJARAN VOKASIONAL OTOMOTIF BAGI PESERTA DIDIK DIFABEL
}

\author{
Galih Wiguna $^{1}$, Wahid Munawar ${ }^{2}$, Sunarto H. Untung ${ }^{3}$ \\ Departemen Pendidikan Teknik Mesin \\ Universitas Pendidikan Indonesia \\ Jl. Dr. Setiabudhi No. 207 Bandung 40154 \\ nakbuai@gmail.com
}

\begin{abstract}
ABSTRAK
Tujuan penelitian ini untuk mendapatkan gambaran mengenai pelaksanaan metode praktik pada pembelajaran keterampilan vokasional otomotif untuk siswa SMALB tunarungu. Metode penelitian yang digunakan yaitu metode penelitian subjek tunggal (single subject research). Desain penelitian menggunakan desain reversal tipe A-B-A, dimana pengukuran fase baseline diulang dua kali. Fase baseline (A1) dilakukan sebelum fase intervensi, kemudian dilakukan fase baseline (A2). Fase baseline pertama dan kedua dilakukan sebanyak empat kali dan fase intervensi dilakukan sebanyak delapan kali. Hasil penelitian menunjukkan bahwa pelaksanaan keterampilan otomotif menggunakan metode praktik mengalami peningkatan. Hal tersebut dapat dilihat pada perubahan level yaitu $+3,+3$ untuk keterampilan membersihkan busi dan $+3,+3$ untuk mengganti oli sepeda motor.
\end{abstract}

Kata kunci: vokasional, otomotif, difabel, baseline, intervensi

\section{PENDAHULUAN}

Pendidikan luar biasa bertujuan membantu peserta didik yang menyandang kelainan fisik dan/atau mental agar mampu mengembangkan sikap, pengetahuan dan keterampilan sebagai pribadi maupun anggota masyarakat dalam mengadakan hubungan timbal balik dengan lingkungan sosial, budaya dan alam sekitar serta dapat mengembangkan kemampuan dalam dunia atau mengikuti pendidikan lanjutan (Depdiknas, (2004).

Keterampilan sangat ditekankan dalam pendidikan khusus dan menjadi hal yang penting dalam pendidikan luar biasa, hal ini sudah diperhatikan dengan adanya keterampilan vokasional pada kurikulum sekolah luar biasa. Pendidikan keterampilan diharapkan menjadi modal bagi anak berkebutuhan khusus untuk bisa lebih mandiri, lebih terampil dan tidak bergantung terhadap orang tua (Efendi, 2009). Berkenaan dengan keterampilan di SLB seorang guru SLB mengatakan bahwa keterampilan sangat penting untuk anak berkebutuhan khusus, karena keterampilan merupakan salah satu bekal bagi anak berkebutuhan khusus untuk lebih bisa mandiri, siap terjun ke dunia kerja dan tidak menjadi beban bagi keluarga. Keterampilan dasar otomotif adalah salah satu keterampilan yang bisa diberikan terhadap

\footnotetext{
${ }^{1}$ Mahasiswa Departemen Pendidikan Teknik Mesin FPTK UPI

${ }^{2}$ Dosen Departemen Pendidikan Teknik Mesin FPTK UPI

${ }^{3}$ Dosen Departemen Pendidikan Teknik Mesin FPTK UPI
} 
anak-anak berkebutuhan khusus. Kebutuhan masyarakat terhadap otomotif semakin meningkat dari tahun ke tahun, sehingga ada peluang yang menjanjikan bagi setiap orang, termasuk anak berkebutuhan khusus untuk mengembangkan keterampilan otomotif (Gintings, 2008). Metode yang banyak diterapkan pada mata pelajaran keterampilan adalah metode konvensional, sehingga membuat peserta didik kurang paham dalam memahami materi yang disampaikan.

Akibat dari kurang tepatnya metode yang digunakan, peserta didik di SLB Negeri Kab. Tasikmalaya menjadi kurang terampil pada bidang keterampilan otomotif dan menjadi beban bagi keluarga. Faktor-faktor yang mempengaruhi belajar 1) faktor internal, yang meliputi keadaan jasmani dan rokhani siswa, 2) faktor eksternal yang merupakan kondisi lingkungan di sekitar siswa, dan 3) faktor pendekatan belajar yang merupakan jenis upaya belajar siswa yang meliputi strategi dan metode yang digunakan siswa untuk melakukan kegiatan mempelajari materi pelajaran (Muhibbinsyah, 2013). Metode belajar yang digunakan akan mempengaruhi terhadap hasil belajar. Ketepatan (efektifitas) penggunaan metode pembelajaran tergantung pada kesesuaian metode pembelajaran dengan beberapa faktor, yaitu tujuan pembelajaran, materi pembelajaran, kemampuan guru, kondisi siswa, sumber atau fasilitas, situasi kondisi dan waktu (Sumiati dan Asra, 2011).

Penggunaan metode pembelajaran harus sesuai dengan tujuan pembelajaran, materi pembelajaran, kemampuan guru, kondisi peserta didik, sumber atau fasilitas, situasi kondisi dan waktu. Komunikasi menjadi kendala untuk anak tunarungu menjadi salah satu faktor penghambat dalam proses pembelajaran (Suyono dan Hariyanto, 2011). Prinsipnya dalam pembelajaran keterampilan otomotif, akan lebih efektif apabila siswa dibimbing dan langsung mengalami materai yang dipelajari. Berdasarkan pendapat Sumiati dan Asra, penulis berpendapat bahwa metode praktik merupakan metode yang dipandang relevan dan tepat untuk proses pembelajaran keterampilan bagi peserta didik tunarungu. Metode praktek lebih mendepankan praktik yang akan memudahkan untuk anak tunarungu menerima informasi dan mengerti tujuan pembelajaran. Tujuan penelitian ini yaitu untuk mencari deskripsi hasil belajar keterampilan otomotif pada komptensi membersihkan busi dan ganti oli pada peserta didik difabel, deskripsi ketercapaian waktu rata-rata kompetensi pada kompetensi membersihkan busi dan ganti oli pada peserta didik difabel.

Metode praktik merupakan upaya memberi kesempatan kepada peserta didik untuk mendapatkan pengalaman langsung. Pengalaman mendorong peserta didik untuk merefleksi atau melihat kembali pengalaman-pengalaman yang dialami. Metode pembelajaran praktik 
adalah sebuah metode pembelajaran dimana peserta didik melaksanakan kegiatan praktik agar memiliki ketegasan atau keterampilan yang lebih tinggi (Jouno, 2012). Metode ini umumnya dilaksanakan dalam pendidikan kejuruan, pendidikan profesi, dan pendidikan dan latihan. Tujuan pembelajaran praktik adalah (1) mengembangkan kualifikasi kunci peserta didik, yang meliputi: kemampian pribadi (fleksibilitas, kesiapan bertanggung jawab, kreativitas, dan kesiapan belajar) dan kemampuan sosial (kesiapan bekerja sama, berkomunikasi, mengatasi masalah). (2) mengembangkan kompetensi peserta didik, yang meliputi: komptensi kejuruan (keterampilan dan pengetahuan kejuruan yang harus dimiliki peserta didik merupakan tujuan dari pengajaran praktik); kompetensi metode (kemampuan untuk mentransfer sesuatu dan kemandirian dalam belajar) dan kompetensi sosial (kemampuan bekerja sama dalam kelompok) (Daryanto, 2013).

\section{METODE PENELITIAN}

Metode yang digunakan adalah metode subjek tunggal yang dikenal dengan istilah single subject research (SSR). Penelitian subjek tunggal yaitu metode yang bertujuan untuk memperoleh data yang diperlukan dengan melihat hasil ada tidaknya pengaruh perubahan yang terjadi dari suatu perlakuan yang diberikan kepada subjek secara berulang-ulang dalam waktu tertentu. Perbandingan tidak dilakukan antar kelompok maupun individu, tetapi dibandingkan dalam subjek yang sama dengan kondisi berbeda. Kondisi yang dimaksud adalah kondisi baseline dan kondisi eksperimen (intervensi). Baseline adalah kondisi dimana pengukuran target behavior dilakukan pada keadaan natural sebelum dilakukan intervensi apapun (Sunanto, 2005). Kondisi eksperimen adalah kondisi dimana suatu intervensi telah diberikan dan target behavior diukur dibawah kondisi tersebut. Pada penelitian subjek tunggal selalu dilakukan perbandingan antara fase baseline dengan sekurang-kurangnya fase intervensi.

Desain penelitian yang digunakan dalam penelitian ini adalah desain A-B-A yang memiliki 2 fase yaitu: A1 (baseline), B (intervensi), dan A2 (baseline). A1 = Baseline Baseline adalah kondisi awal kemampuan keterampilan subjek sebelum diberi perlakuan (intervensi). Pengukuran baseline dilakukan sampai data stabil. $\mathrm{B}=$ Intervensi Intervensi adalah kondisi keterampilan subjek selama memperoleh perlakuan, yaitu pembelajaran keterampilan memelihara busi, dan ganti oli. Perlakuan dan pengukuran dilakukan sampai data menjadi stabil. A2 = baseline Baseline yang kedua yaitu kondisi baseline sebagai evaluasi sejauh mana intervensi diberikan terhadap subjek sampai data stabil. 


\section{HASIL PENELITIAN}

Data hasil analisis dalam kondisi dan antar kondisi pada peserta didik yang telah dilakukan dan diperoleh hasil yang telah diringkas pada uraian di bawah ini.

Tabel 1. Hasil analisis dalam kondisi (membersihkan busi)

\begin{tabular}{|c|c|c|c|}
\hline Kondisi & Baseline (A1) & Intervensi $(\mathrm{B})$ & Baseline (A2) \\
\hline 1. Panjang Kondisi & 4 & 8 & 45 \\
\hline $\begin{array}{l}\text { 2. Estimasi Kecenderungan } \\
\text { Arah }\end{array}$ & $(=)$ & & \\
\hline 3. Kecenderungan Stabilitas & Stabil & Stabil & Stabil \\
\hline 4. Jejak Data & $(=)$ & & $(+)$ \\
\hline 5. Level Stabilitas dan & $\underline{\text { Stabil }}$ & $\underline{\text { Stabil }}$ & $\underline{\text { Stabil }}$ \\
\hline Rentang & $9-10$ & $\overline{10-11}$ & $\overline{10-11}$ \\
\hline \multirow[t]{2}{*}{ 6. Level Perubahan } & $\underline{10-9}$ & $\underline{11-10}$ & $\underline{11-10}$ \\
\hline & +1 & +1 & +1 \\
\hline
\end{tabular}

Tabel 2. Hasil analisis antar kondisi peserta (membersihkan busi)

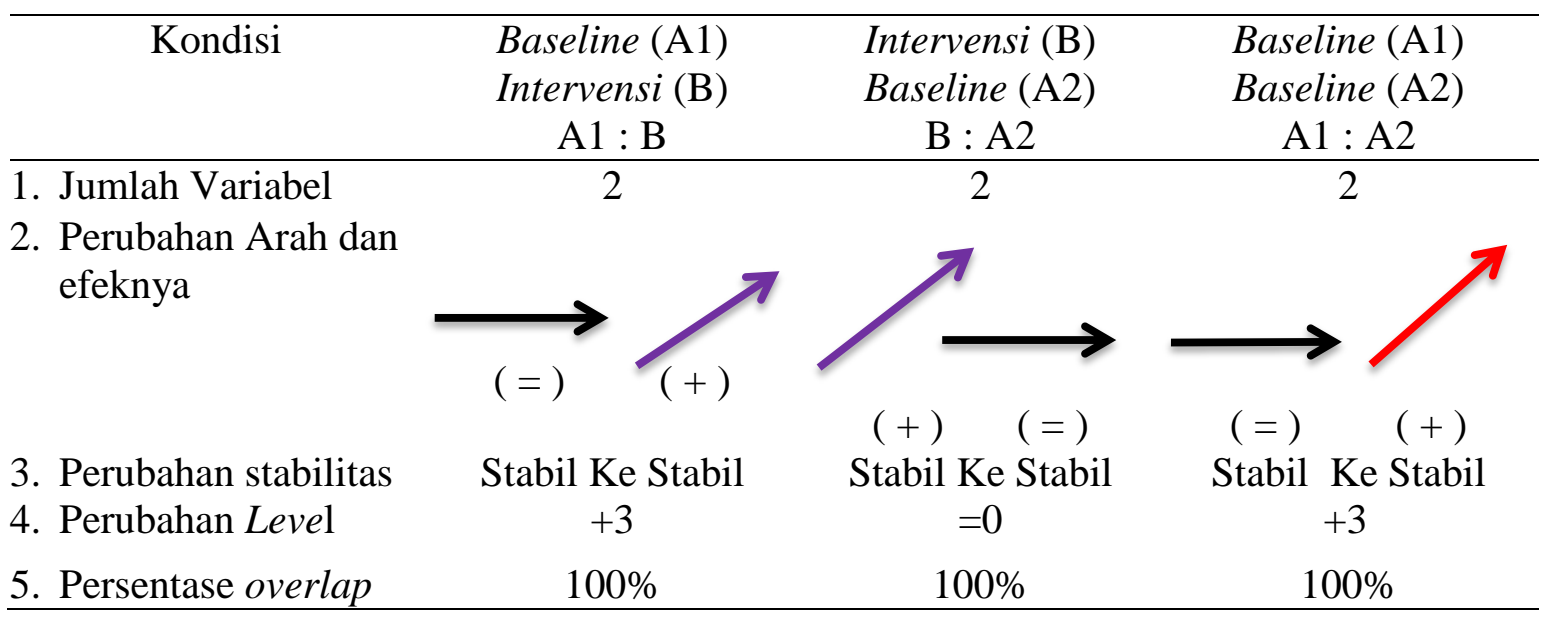


Tabel 3. Hasil analisis dalam kondisi peserta didik (mengganti oli)

\begin{tabular}{|c|c|c|c|}
\hline Kondisi & $\begin{array}{l}\text { Baseline (A1) } \\
\text { Intervensi }(\mathrm{B}) \\
\text { A1 : B }\end{array}$ & $\begin{array}{l}\text { Intervensi }(\mathrm{B}) \\
\text { Baseline (A2) } \\
\text { B : A2 }\end{array}$ & $\begin{array}{c}\text { Baseline (A1) } \\
\text { Baseline (A2) } \\
\text { A1 : A2 }\end{array}$ \\
\hline 1. Jumlah Variabel & 2 & 2 & 2 \\
\hline $\begin{array}{l}\text { 2. Perubahan Arah dan } \\
\text { efeknya }\end{array}$ & & & \\
\hline $\begin{array}{l}\text { 3. Perubahan stabilitas } \\
\text { 4. Perubahan Level }\end{array}$ & $\begin{array}{l}\text { Stabil Ke Stabil } \\
+3\end{array}$ & $\begin{array}{c}(+) \quad(=) \\
\begin{array}{c}\text { Stabil Ke Stabil } \\
=0\end{array}\end{array}$ & $\begin{array}{cc}(=) & (+) \\
\text { Stabil } & \text { Ke Stabil } \\
& +3\end{array}$ \\
\hline 5. Persentase overlap & $100 \%$ & $100 \%$ & $100 \%$ \\
\hline
\end{tabular}

Tabel 4. Hasil analisis antar kondisi peserta (mengganti oli)

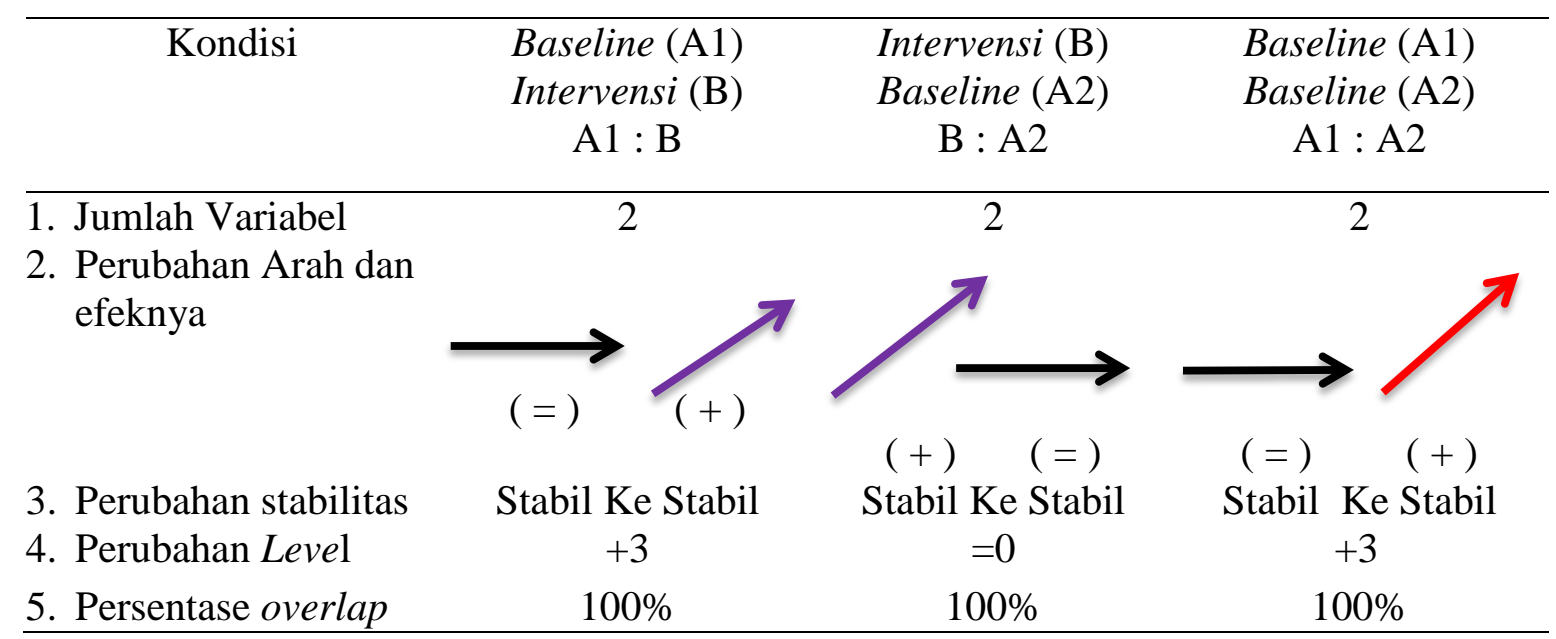

\section{PEMBAHASAN}

Hasil analisis dalam kondisi seperti tergambar dalam tabel menggambarkan bahwa dalam penelitian dalam panjang kondisi sebanyak 16, yaitu 4 kondisi pada fase baseline (A1), 8 kondisi pada fase intervensi (B), dan 4 kondisi fase baseline (A2). Estimasi kecenderungan arah semua peserta didik menggambarkan perubahan pada fase baseline (A1) sebelum dilakukan intervensi, estimasi kemampuan keterampilan membersihkan busi dan mengganti oli sepeda motor menggambarkan mendatar. Intervensi atau perlakuan diberikan pada fase intervensi (B) estimasi kecenderungan arah meningkat, begitu juga pada fase baseline (A2) setelah dilakukan fase intervensi menggambarkan cenderung meningkat. 
Stabilitas data namapak pada fase intervensi (B) dan fase baseline (A2) menggambarkan bahwa kemampuan keterampilan membersihkan busi dan mengganti oli selama diberikan intervensi dan setelah diberikan intervensi menunjukkan stabil. Jejak data menggambarkan arah positif (+) mengandung makna bahwa perubahan kemampuan keterampilan membersihkan busi dan mengganti oli sepeda motor ke arah positif atau membaik (Batang, 2011).

Perubahan level menggambarkan arah yang meningkat artinya kemampuan keterampilan membersihkan busi dan mengganti oli tiap fase pada intervensi menggambarkan peningkatan. Perubahan ini menggambarkan bahwa penggunaan metode praktik dalam proses belajar memiliki pengaruh positif terhadap kemampuan peserta didik pada keterampilan membersihkan busi dan mengganti oli sepeda motor (Arifin, 2009).

Analisis antar kondisi menggambarkan data overlap dengan membandingkan fase baseline (A1) sebelum dilakukan intervensi, dengan fase intervensi (B) semua peserta didik menggambarkan $0 \%$, semakin kecil nilai overlap mengandung makna bahwa intervensi (pengaruh metode praktik) berpengaruh terhadap target behavior berupa kemampuan keterampilan membersihkan busi dan mengganti oli sepeda motor.

Pelaksanaan hasil belajar keterampilan membersihkan busi dan mengganti oli kedua peserta didik mengalami peningkatan. Peningkatan dapat dilihat dengan adanya perubahan level. Jumlah skor keterampilan pada fase baseline (A2) setelah diberikan intervensi atau perlakuan jauh lebih besar jika dibandingkan dengan data jumlah skor keterampilan pada fase baseline (A1) sebelum diberikan intervensi atau perlakuan. Intervensi atau perlakuan berupa pembelajaran keterampilan otomotif menggunakan metode praktik diberikan terhadap peserta didik memberikan hal yang positif terhadap perubahan perilaku subjek.

Penggunaan metode praktik pada anak tunarungu yang mempunyai kesulitan dalam berkomunikasi dilihat sangat tepat, karena metode praktik lebih mendepankan praktik yang memudahkan anak tunarungu mengerti akan maksud dan tujuan pembelajaran. Metode praktik memberikan pengalaman langsung peserta didik untuk membersihkan busi dan mengganti oli sepeda motor, sehingga peserta didik lebih cepat mendalami keterampilan yang diberikan. Sebagai mana kelebihan metode praktik (Juono, 2013) antara lain:

1. Diperolehnya perubahan perilaku ranah psikomotor dalam bentuk ketrampilan melakukan pekerjaannya sesuai dengan tuntutan profesinya kelak.

2. Mempermudah dan memperdalam pemahaman tentang berbagai teori yang terkait dengan praktek yang sedang dikerjakannya. 
3. Meningkatkan motivasi dan gairah belajar siswa karena pekerjaan yang dilakukan memberikan tantangan baru baginya.

4. Meningkatkan kepercayaan diri siswa tentang profesionalisme yang dimilikinya.

\section{KESIMPULAN}

Kesimpulan penelitian ini yaitu hasil belajar memelihara busi setiap fase mengalami peningkatan. Perubahan level semua peserta didik menunjukan arah yang meningkat. Hasil belajar mengganti oli antar kondisi setiap fase mengalami peningkatan. Perubahan level semua peserta didik menunjukan arah yang meningkat. Ketercapaian waktu membersihkan busi setiap fase mengalami peningkatan. Perubahan rata-rata ketercapaian waktu peserta didik menunjukan arah meningkat. Ketercapaian waktu bidang keahlian mengganti oli setiap fase mengalami peningkatan. Perubahan rata-rata ketercapaian waktu peserta didik menunjukan arah meningkat.

\section{DAFTAR PUSTAKA}

Arifin, Z (2009). Evaluasi Pembelajaran. Bandung: PT Remaja Rosdakarya.

Daryanto. (2013). Strategi Tahapan Mengajar dan Bekal Keterampilan Dasar bagi Guru. Bandung: CV Yrama Widya.

Depdiknas, (2004). Anak Berkebutuhan Khusus. Jakarta: Direktorat Pendidikan Luar Biasa.

Efendi, M. (2009). Pengantar psikopedagogik anak berkelainan. Jakarta: PT Bumi Aksara.

Gintings, A. (2008). Essensi Praktis Belajar dan Pembelajaran, Bandung: Humaniora.

Juono, Ribut . (2012). Metode Pembelajaran. [Online]. Tersedia: http://juonorp.blogspot. com/2013/05/metode-pembelajaran.html. [11-05-14].

Muhibbinsyah, (2013). Psikologi Pendidikan Dengan Pendekatan Baru. Bandung: PT Remaja Rosada.

Sumiati dan Asra. (2011). Metode Pembelajaran. Bandung: CV Wacana Prima.

Sunanto, J. ( 2005 ). Pengantar penelitian dengan subyek tunggal. Bandung: Universitas Pendidikan Indonesia.

Suyono dan Hariyanto, (2011). Belajar dan Pembelajaran. Bandung: PT. Remaja Rosdakarya.

Batang, Y. (2011). Cara Mengganti Oli Sendiri Pada Sepeda Motor. [Online]. Tersedia: http://yudibatang.wordpress.com/2011/07/11/cara-mengganti-oli-sendiri-pada-sepedamotor/ [24-05-14]. 